\title{
Genetic factors are important determinants of neurodevelopmental outcome after repair of tetralogy of Fallot
}

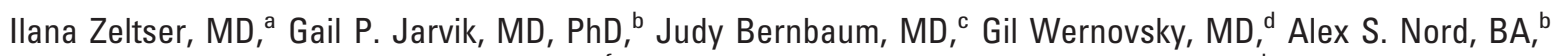
Marsha Gerdes, PhD, ${ }^{\mathrm{e}}$ Elaine Zackai, MD, ${ }^{\mathrm{f}}$ Robert Clancy, MD, ${ }^{\mathrm{g}}$ Susan C. Nicolson, MD, ${ }^{\mathrm{h}}$ Thomas L. Spray, MD, and J. William Gaynor, MDi

From the Division of Cardiology, The Children's Medical Center at Dallas, ${ }^{a}$ Dallas, Tex; Department of Medicine (Medical Genetics), University of Washington, ${ }^{\mathrm{b}}$ Seattle, Wash; and Divisions of General Pediatrics, Cardiology, ${ }^{\mathrm{d}}$ Psychology, ${ }^{\mathrm{e}}$ Genetics, ${ }^{\mathrm{f}}$ Neurology, ${ }^{\mathrm{g}}$ Cardiothoracic Anesthesia, ${ }^{\mathrm{h}}$ and Cardiothoracic Surgery, ${ }^{\mathrm{i}}$ The Children's Hospital of Philadelphia, Pa.

Research supported by an American Heart Association National Grant-in-Aid (9950480N), the Pew Biomedical Scholar Program, and the Fannie E. Rippel Foundation.

Research presented at the American Heart Association Scientific Sessions 2004, Orlando, Florida, November 7-10, 2004.

Received for publication Feb 1, 2007; revisions received April 19, 2007; accepted for publication April 26, 2007

Address for reprints: Ilana Zeltser, MD, Division of Cardiology, The University of Texas at Southwestern Medical Center, Children's Medical Center at Dallas, 1935 Motor Street, Dallas, TX 75235 (E-mail: ilana.zeltser@childrens.com).

J Thorac Cardiovasc Surg 2008;135:91-7

$0022-5223 / \$ 34.00$

Copyright $(92008$ by The American Association for Thoracic Surgery

doi:10.1016/j.jtcvs.2007.04.074
Objective: Adverse neurodevelopmental sequelae are common in children with congenital heart defects. Tetralogy of Fallot is part of the clinical phenotype of many genetic syndromes. We evaluated the determinants of neurodevelopmental outcome in patients with tetralogy of Fallot.

Methods: We performed a subgroup analysis of children with tetralogy of Fallot undergoing complete repair before 6 months of age who were enrolled in a trial assessing apolipoprotein E genotype as a predictor of neurodevelopmental outcome. Assessment included genetic evaluation, neurologic examination, and the Bayley Scales of Infant Development-II, yielding the Mental Developmental Index and Psychomotor Developmental Index.

Results: Sixty children were tested at 1 year of age. A confirmed or suspected genetic syndrome was identified in $18.3 \%$. The mean Mental Developmental Index was $89 \pm 13$, and the mean Psychomotor Developmental Index was $81 \pm 17$. Scores for the Mental Developmental Index $(76 \pm 13$ vs $92 \pm 11)$ and Psychomotor Developmental Index $(63 \pm 13$ vs $85 \pm 15)$ were significantly lower for patients with genetic syndromes. The presence of a genetic syndrome was a predictor of lower Mental Developmental Index and Psychomotor Developmental Index $(P=$ .002 and $P=.001)$. The presence of tetralogy of Fallot with pulmonary atresia and the apolipoprotein E $\varepsilon 2$ allele were predictive of a lower Mental Developmental Index $(P=.001$ and $P=.035)$. No other preoperative or operative variables were predictive of worse neurodevelopmental outcome.

Conclusions: At 1 year of age after repair of tetralogy of Fallot, most patients had neurodevelopmental scores within the normal range. Genetic syndromes and the apolipoprotein E $\varepsilon 2$ allele were important risk factors for neurodevelopmental dysfunction and accounted for some interindividual differences in outcome.

$\mathrm{T}$ Tetralogy of Fallot (TOF) is one of the most common forms of congenital heart disease, with a prevalence of 0.026 to 0.048 per 1000 live births. ${ }^{1}$ In the current surgical era, complete intracardiac repair for TOF is commonly performed during infancy, with actuarial survivals of $95 \%$ after 5 years and $86 \%$ after 30 years. ${ }^{2}$ Although the long-term mortality rate after TOF repair is low, there is growing recognition and concern that these patients are at increased risk of adverse neurodevelopmental (ND) outcomes. Preoperative risk factors, such as chronic hypoxemia, hypoperfusion, acidosis, and thromboembolic events, have been identified as risk factors for adverse ND outcomes in this patient population. ${ }^{3-5}$ Intraoperative management strategies, including the duration of cardiopulmonary bypass (CPB), use and duration of deep hypothermic circulatory arrest (DHCA), hemodilution, degree of hypothermia, and blood gas management, have been 


\author{
Abbreviations and Acronyms \\ $\mathrm{APOE}=$ apolipoprotein $\mathrm{E}$ \\ $\mathrm{CPB}=$ cardiopulmonary bypass \\ $\mathrm{DHCA}=$ deep hypothermic circulatory arrest \\ MDI $=$ Mental Developmental Index \\ ND = neurodevelopmental \\ PDI = Psychomotor Developmental Index \\ $\mathrm{SD}=$ standard deviation \\ TOF $=$ tetralogy of Fallot
}

implicated as potential contributors to cerebral injury. ${ }^{6-10}$ However, these factors do not fully account for the differences in ND outcome observed among individuals with TOF who underwent comparable surgical procedures, suggesting that the pathogenesis of adverse ND outcomes in this patient population is multifactorial.

TOF is a phenotypic feature or an associated clinical finding of many genetic syndromes and chromosomal anomalies associated with impaired ND. ${ }^{11}$ As many as $16 \%$ of patients with TOF have 22q11 microdeletions, Down syndrome, Alagille's syndrome, Cat Eye syndrome, or CHARGE and VATER associations. ${ }^{11-15}$ Overall, patients with TOF have been noted to have poorer ND outcomes than the healthy population. ${ }^{3,16}$ DeMaso and associates ${ }^{17}$ reported that $22 \%$ of patients with TOF, most of whom underwent complete surgical repair, scored less than 80 on standardized intelligence quotient testing, approximately 1.5 standard deviations (SDs) less than the expected mean score of 100 . Few data are available regarding ND outcomes for patients after surgical repair of TOF in infancy wherein confounding genetic variables are taken into consideration.

In addition, genetic polymorphisms exist that may impair neuroresiliency and increase susceptibility to neurologic injury after infant heart surgery. Apolipoprotein E (APOE) is an important regulator of cholesterol metabolism in the central nervous system and plays a pivotal role in the mobilization and redistribution of cholesterol and phospholipids during neuronal remodeling. ${ }^{18,19}$ Specifically, APOE e2 allele carriers have been shown to have lower scores on the Psychomotor Development Index (PDI) of the Bayley Scales of Infant Development-II at 1 year of age after neonatal and infant cardiac surgery. ${ }^{20}$

The purpose of this study was to determine the frequency of abnormal ND outcomes in 1-year-old patients with TOF after surgical repair. In addition, we sought to determine the role of genetic factors, including APOE polymorphisms, as determinants of poor ND outcomes in this patient population.

\section{Materials and Methods}

This study constitutes a post hoc analysis of a prospective observational cohort study assessing the effects of polymorphisms of
APOE on ND outcomes in patients aged 6 months or less undergoing surgical repair for congenital heart disease. ${ }^{20}$ The institutional review board at The Children's Hospital of Philadelphia approved the study. Informed consent was obtained from the parent or guardian.

\section{Patient Population}

Between October of 1998 and April of 2003, infants with TOF (TOF/pulmonary stenosis or TOF/pulmonary atresia) undergoing complete biventricular repair by the age of 6 months were eligible for the study. Infants with TOF/absent pulmonary valve and TOF/ pulmonary atresia with multiple aortopulmonary collaterals were excluded. Other exclusion criteria included (1) major recognizable congenital defects, (2) recognizable genetic or phenotypic syndrome other than chromosome 22q11 microdeletions, and (3) language other than English spoken at home.

Operations were performed at a single institution by 4 cardiac surgeons with a team of dedicated cardiac anesthesiologists. Alphastat blood gas management was used. DHCA was used at the discretion of the surgeon. Before DHCA, patients underwent cooling with topical hypothermia and $\mathrm{CPB}$ to a nasopharyngeal temperature of $18^{\circ} \mathrm{C}$. Modified ultrafiltration was performed in all patients.

\section{One-year Neurodevelopmental Examination}

The protocol for ND examination has been described. ${ }^{20}$ In short, children were evaluated at 12 months of age \pm 2 weeks, adjusted appropriately for prematurity. Development was assessed by the Bayley Scales of Infant Development-II, which is composed of 2 separate scores. The PDI assesses fine and gross motor skills, and the Mental Developmental Index (MDI) evaluates cognition, language, memory, problem-solving, and social skills. Both the PDI and MDI yield scores that are normalized to a mean of $100 \pm 15$. Therefore, a score of 70 or less is greater than 2 SDs below the mean.

In addition, the neurologic evaluation included a medical history, growth measurements, and a complete neurologic examination assessing active and passive tone, reflexes, gross motor skills, and visual and auditory responses by a single developmental pediatrician. The results of the neurologic examination were considered "normal" if no abnormalities or only mild abnormalities that did not affect motor skills were found, "suspect" when there was a moderate degree of abnormality, and "abnormal" when significant abnormalities of tone, reflexes, or motor skills were present. Microcephaly was defined as a head circumference less than or equal to the 5 th percentile for age.

Patients were also evaluated by a genetic dysmorphologist. Given the difficulty in detecting dysmorphic features and genetic syndromes in the neonatal period, some children with unrecognized genetic abnormalities had been enrolled as infants. Chromosome analysis and testing for microdeletions of chromosome 22q11 were performed as indicated.

\section{Statistical Analysis}

Continuous data are expressed as mean $\pm \mathrm{SD}$. Independent $t$ tests were used for comparison of continuous variables, and chi-square and Fisher exact tests were used for comparison of discrete variables as appropriate. Regression analysis was used to assess the association between risk factors and PDI and MDI scores. Initial 
TABLE 1. Baseline characteristics* and intraoperative statistics of the study group and enrolled patients who did not return for neurodevelopmental testing

\begin{tabular}{|c|c|c|c|}
\hline & $\begin{array}{c}\text { Study group } \\
\mathrm{n}=60\end{array}$ & $\begin{array}{l}\text { rolled patients } \\
\text { did not return } \\
n=23\end{array}$ & $P$ value \\
\hline \multicolumn{4}{|l|}{ Baseline characteristics } \\
\hline Male:female, ratio & $31: 29$ & $15: 08$ & .387 \\
\hline Race & & & .336 \\
\hline White & $45(75 \%)$ & $13(70 \%)$ & \\
\hline Hispanic & $0(0 \%)$ & $1(4 \%)$ & \\
\hline Black & $7(12 \%)$ & $4(17 \%)$ & \\
\hline Other & $8(13 \%)$ & $2(9 \%)$ & \\
\hline APOE allele group & & & .469 \\
\hline 22 and 23 & $5(9 \%)$ & $3(14 \%)$ & \\
\hline 33 & $35(60 \%)$ & $15(68 \%)$ & \\
\hline 34 and 44 & $18(31 \%)$ & $4(18)$ & \\
\hline SES & $4.22 \pm 0.92$ & No data & \\
\hline Gestational age, wk & $38.0 \pm 3.0$ & $39 \pm 1.0$ & .488 \\
\hline Birth weight, kg & $3.0 \pm 0.7$ & $3.1 \pm 0.6$ & .549 \\
\hline Head circumference, cm & $33.0 \pm 2.3$ & $33.5 \pm 1.5$ & .571 \\
\hline Microcephaly (head circumference $\leq 5 \%$ ), $n$ & $11(18 \%)$ & $5(22 \%)$ & .967 \\
\hline Caesarean delivery & $40(67 \%)$ & $13(57 \%)$ & .545 \\
\hline Multiple birth & $4(7 \%)$ & $0(0 \%)$ & .486 \\
\hline Genetic disorder & $11(18 \%)$ & $4(17 \%)$ & .827 \\
\hline Diagnosis of TOF/PA & $3(5 \%)$ & $1(4 \%)$ & .654 \\
\hline Apgar 1 & $8.00 \pm 1.44$ & $8.14 \pm 0.57$ & .530 \\
\hline Apgar 5 & $8.79 \pm 0.55$ & $8.95 \pm 0.50$ & .230 \\
\hline Delayed sternal closure & $3(5 \%)$ & $0(0 \%)$ & .663 \\
\hline ECMO/LVAD & $1(2 \%)$ & $0(0 \%)$ & .616 \\
\hline Preoperative prostaglandin, $\mathrm{n}$ & $4(7 \%)$ & $1(4 \%)$ & .869 \\
\hline \multicolumn{4}{|l|}{ Operative data } \\
\hline Age at surgery, mo & $2.64 \pm 1.4$ & $3.24 \pm 1.8$ & .177 \\
\hline Weight at surgery, $\mathrm{kg}$ & $4.8 \pm 1.53$ & $5.0 \pm 1.36$ & .625 \\
\hline Single operative procedure, $\mathrm{n}$ & $59(98 \%)$ & $20(87 \%)$ & .111 \\
\hline Total support time, $\min$ & $68.0 \pm 21$ & $89 \pm 34$ & .076 \\
\hline Total CPB time, min & $56.3 \pm 19.7$ & $83 \pm 37$ & .018 \\
\hline Use of DHCA, $n$ & $22(37 \%)$ & $4(17 \%)$ & .153 \\
\hline Total DHCA time, min & $11.7 \pm 17.3$ & $6.0 \pm 12$ & .081 \\
\hline Max DHCA & $11.70 \pm 17.31$ & $5.61 \pm 12.60$ & .083 \\
\hline HCT & $26.45 \pm 4.56$ & $26.70 \pm 3.84$ & .806 \\
\hline NP_temp & $23.38 \pm 4.77$ & $24.48 \pm 3.76$ & .277 \\
\hline
\end{tabular}

APOE, Apolipoprotein E; SES, socioeconomic status; TOF/PA, tetralogy of Fallot/pulmonary atresia; ECMO/LVAD, extracorporeal membrane oxygenation/left ventricular assist device; $C P B$, cardiopulmonary bypass; $D H C A$, deep hypothermic circulatory arrest; $H C T$, hematocrit; $N P$, nasopharyngeal.

${ }^{*}$ Reflects baseline characteristics that were retrospectively analyzed at the 1-year mark. †Max DHCA refers to the longest, single-time exposure to DHCA.

univariate analysis was performed on potential predictors of ND outcome, including gestational age, ethnicity, socioeconomic status, birth weight, birth length, birth head circumference, sex, delivery method (caesarean or vaginal), multiple gestation birth, 1and 5- minute Apgar scores, preoperative intubation and prostaglandin use, presence of a confirmed or suspected genetic syndrome, $A P O E$ genotype, age and weight at the time of surgery, extracorporeal membrane oxygenation/left ventricular assist device, delayed sternal closure, hematocrit (first value obtained on bypass after hemodilution), intraoperative support time (CPB and DHCA), number of operations and episodes of $\mathrm{CPB}$, and use and duration of DHCA. With respect to the APOE genotype analysis, subjects were grouped into the $\varepsilon 2$ group ( $\varepsilon 2 \varepsilon 2$ and $\varepsilon 2 \varepsilon 3), \varepsilon 3 \varepsilon 3$ group, and $\varepsilon 4$ group ( $\varepsilon 3 \varepsilon 4$ and $\varepsilon 4 \varepsilon 4$ ). Two patients with $\varepsilon 2 \varepsilon 4$ were excluded from the analysis because of the opposing effects of $\varepsilon 2$ and $\varepsilon 4$ in Alzheimer disease.

Variables that were marginally significant at $P$ less than .10 were then included in stepwise multivariable regression analysis to identify independent predictors, and the most parsimonious model was used. Because the presence of a confirmed or suspected genetic syndrome was such a strong univariate predictor of ND outcome, the cohort was divided on the basis of whether a genetic 


\section{Bayley Scales of Infant Development}

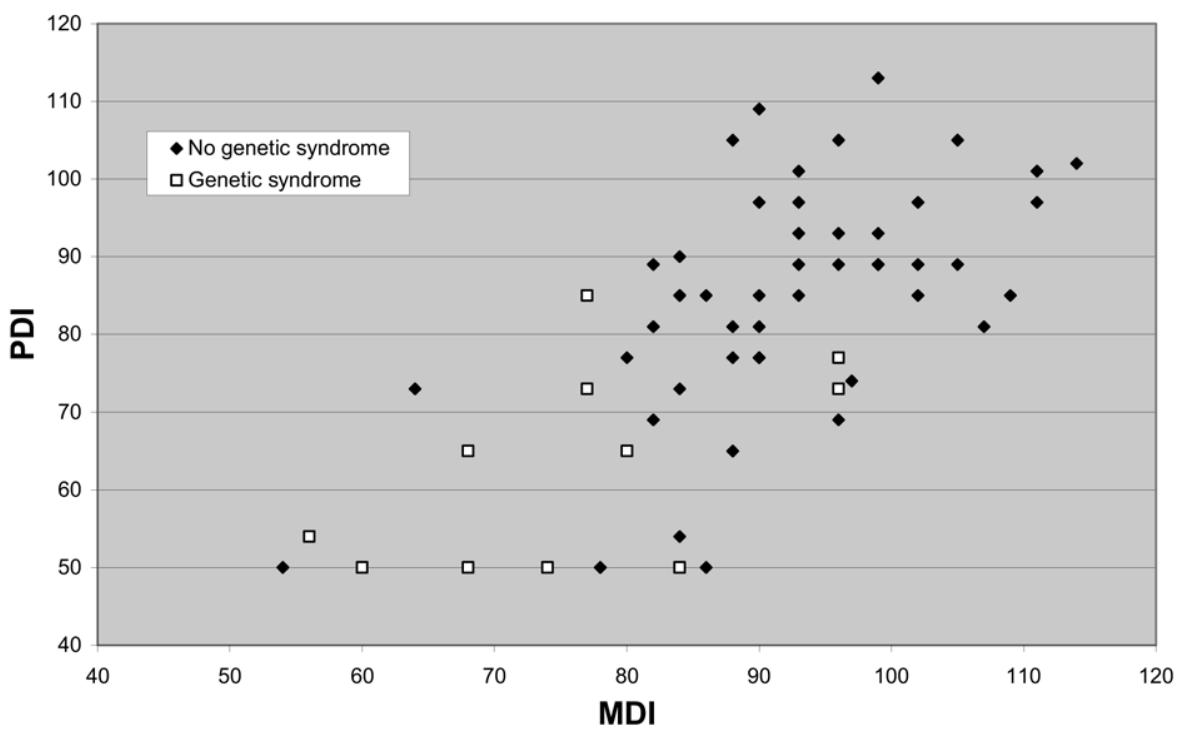

Figure 1. Comparison of ND scores for MDI and PDI between patients with TOF with a coexisting genetic syndrome versus those without at 1 year of age. Both MDI and PDI are normalized to $100 \pm 15$. MDI, Mental Developmental Index; PDI, Psychomotor Development Index. syndrome was detected. Separate multivariable analyses were performed on each of these group's predictors.

\section{Results}

Between October 1, 1998, and March 24, 2003, 111 eligible patients were diagnosed with TOF and underwent surgery with $\mathrm{CPB}$ at the age of 6 months of less. A total of 96 patients (83\%) were enrolled in the prospective study. Eighty-three patients $(86 \%)$ underwent complete intracardiac repair and were eligible for this study. The remaining 13 patients underwent a palliative surgical procedure or had complex anatomy (absent pulmonary valve, multiple aortopulmonary collaterals) and thus did not meet inclusion criteria. There was no surgical mortality in the study group. Of the 83 potential patients, 60 (72\%) returned for the 1-year evaluation and constitute the study population. The primary reason for not returning was lack of funds for travel.

The baseline characteristics and intraoperative details are presented in Table 1. Overall, there was no gender predominance in our patient population. Fifty-nine patients (98\%) underwent a single surgical procedure. One patient required reoperation before testing at 1 year. DHCA was used in 22 procedures $(37 \%)$. Five patients $(8 \%)$ required multiple periods of CPB during the initial repair. There was no statistical difference in baseline characteristics between the study group and those enrolled patients who did not return for ND testing. However, longer CPB, and therefore total support, times had been used for those patients who did not return for a 1-year assessment compared with the study group.

ND testing was performed, on average, at $12.24 \pm 0.6$ months. The mean weight was $8.7 \pm 1.2 \mathrm{~kg}$, and the mean head circumference was $45.7 \pm 1.9 \mathrm{~cm}$. Fifteen patients $(25 \%)$ had microcephaly $(<5 \%)$ at the time of testing, 5 of whom had been microcephalic at birth. The neuromuscular examination results were abnormal in 5 patients $(8.3 \%)$ and suspect in 13 patients (21.7\%). Varying degrees of hypotonia accounted for all abnormalities in the neuromuscular examination.

Neonatal recognition of dysmorphic features may be difficult; therefore, some patients were enrolled in whom the diagnosis of a genetic syndrome was not made until the 1-year evaluation. Therefore, although patients with recognized genetic syndromes (eg, trisomy 21), except for 22q11 microdeletions, were not enrolled, a confirmed or suspected genetic syndrome was identified at the 1-year evaluation in $18.3 \%$ of the patients. Testing for 22q11 microdeletions was performed in 57 of 60 patients $(95 \%)$ and identified in 6 patients. Overall genetic syndromes were identified in 11 patients, including 22q11 (6), CHARGE association (2), VATER association (1), Holt-Oram (1), and an undiagnosed syndrome (1). The APOE allele frequencies were 5.8\%, $76.7 \%$, and $17.5 \%$ for $\varepsilon 2, \varepsilon 3$, and $\varepsilon 4$, respectively, as expected for a primarily white population. There were no $\varepsilon 2 \varepsilon 2$ carriers in this study population.

For the entire cohort, the mean MDI was $89 \pm 13$ and the mean PDI was $81 \pm 17$. When the scores were analyzed in the context of an underlying genetic syndrome (Figure 1), scores for the MDI were significantly lower for those with a genetic syndrome $(76 \pm 13)$ versus those without (92 $\pm 11)$. Only $4 \%(2 / 49)$ without an underlying genetic syndrome scored below 2 SDs of normal on the MDI, in contrast with $27.2 \%(3 / 11)$ with a genetic syndrome who 

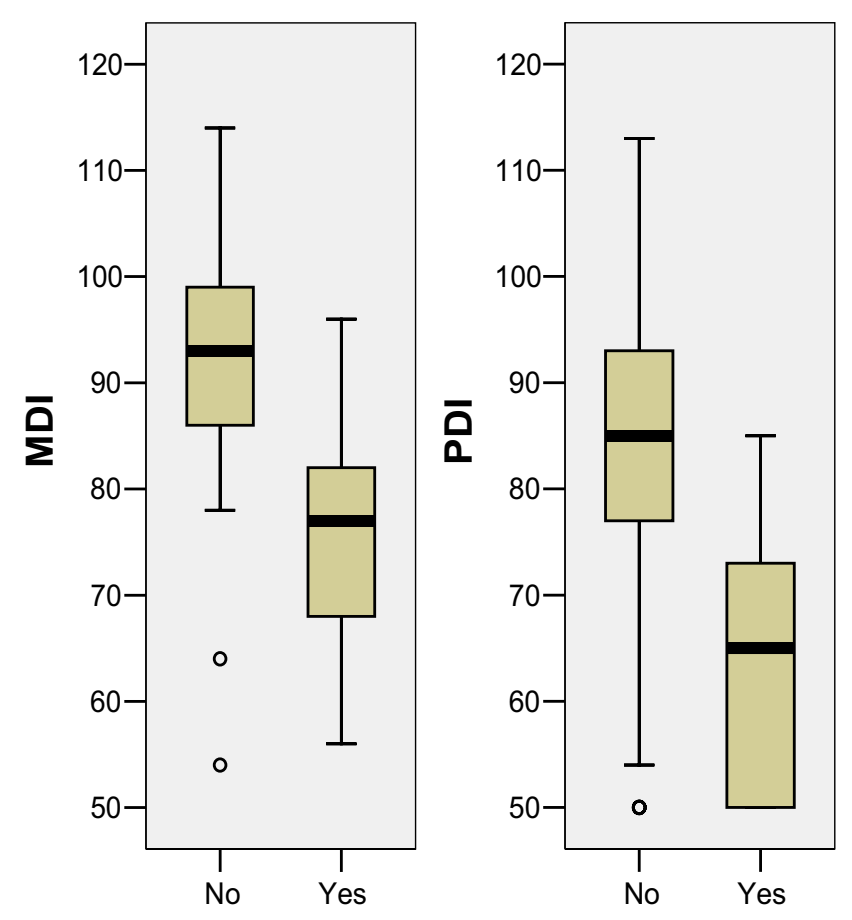

Genetic Syndrome

Figure 2. In the absence of a genetic syndrome, MDI and PDI scores for children who underwent surgical repair of TOF are within 1 SD of accepted normal values (100 \pm 15$)$. Patients with TOF and a coexisting genetic syndrome have significantly lower scores for both MDI and PDI compared with those without genetic syndromes. TOF, Tetralogy of Fallot; PDI, Psychomotor Development Index.

scored below 2 SDs of the norm. Similarly, scores for the PDI were significantly lower for those with a genetic syndrome $(63 \pm 13)$ versus those without $(85 \pm 15)$ (Figure 2). Fourteen percent of patients (7/49) without a genetic syndrome scored below 2 SDs of normal on the PDI, compared with $63.6 \%$ of patients (7/11) with a genetic syndrome. Of note, there was no difference between MDI and PDI scores among those with a genetic syndrome when specifically comparing those with the 22q11 microdeletion $(n=6)$ versus those without $(\mathrm{n}=5)$.

In the absence of the APOE $\varepsilon 2$ allele, most 1-year-old children had normal MDI scores $(91 \pm 2)$, with only $7.3 \%$ (4/55) scoring below 2 SDs of normal. In contrast, APOE $\varepsilon 2$ allele carriers had lower MDI scores $(78 \pm 8)$ compared with those without the $\varepsilon 2$ allele, of whom $40 \%$ (2/5) scored below 2 SDs of normal. PDI scores did not vary across APOE genotypes.

Table 2 shows the univariate regression results for factors predicting MDI and PDI at a $P$ value less than .10, the cutoff used for inclusion in the multivariate analysis. Table 3 shows
TABLE 2. Univariate regression models for Mental Developmental Index and Psychomotor Developmental Index

\begin{tabular}{lccc}
\hline \multicolumn{4}{c}{ Univariate models (N = 60) } \\
\hline Variable & B & SE & P value \\
\hline MDI & & & \\
Diagnosis of TOF/PA & -29.965 & 6.712 & .000 \\
Genetic disorder & -16.082 & 3.840 & .000 \\
PGE & -22.643 & 6.113 & .000 \\
Total_DHCA.surg1 & -0.280 & 0.092 & .003 \\
DHCA_max & -0.280 & 0.092 & .003 \\
DHCA_total & -0.276 & 0.091 & .004 \\
NP_temp & 0.882 & 0.340 & .012 \\
DHCA.number & -7.666 & 3.106 & .017 \\
Weight.surg1 & 2.367 & 1.076 & .032 \\
Surgeon & & & .063 \\
Operations & -16.690 & 9.188 & .074 \\
Bypass & -10.618 & 5.974 & .081 \\
APOE.genotype & & & .087 \\
PDI & & & \\
Genetic disorder & -21.826 & 4.849 & .000 \\
Diagnosis of TOF/PA & -27.088 & 9.345 & .005 \\
PGE & -20.607 & 8.307 & .016 \\
Weight.surg1 & 3.109 & 1.380 & .028 \\
Total_DHCA.surg1 & -0.258 & 0.122 & .039 \\
DHCA_max & -0.258 & 0.122 & .039 \\
DHCA_total & -0.253 & 0.121 & .042 \\
Apgar_1 & 2.729 & 1.490 & .072 \\
NP_temp & 0.775 & 0.450 & .090 \\
\hline
\end{tabular}

$M D I$, Mental Developmental Index; $S E$, standard error; TOF/PA, tetralogy of Fallot/pulmonary atresia; $P G E$, prostaglandin; $D H C A$, deep hypothermic circulatory arrest (DHCA_max: single maximal exposure to DHCA); $N P$, nasopharyngeal; $A P O E$, apolipoprotein $\mathrm{E}$.

the final models, based on stepwise regression analysis. The presence of a genetic syndrome was identified as a predictor of lower MDI $(P=.02)$ and PDI $(P<.001)$ scores in the final models. In addition, the presence of an APOE $\varepsilon 2$ allele $(P=$ $.02)$ and diagnosis of TOF with pulmonary atresia $(P<.001)$ were predictive of lower MDI scores in the multivariate analysis. When only subjects with no genetic syndrome were considered, the APOE $\varepsilon 4$ allele was also associated with a decreased MDI score. No predictors other than the presence of a genetic syndrome were significantly associated with the PDI score in the final models. Birth weight, gestational age, socioeconomic status, and age at surgery were not predictive of adverse ND outcomes. Intraoperative variables, including use or duration of DHCA, total support time, and surgeon, were not significantly associated with lower ND scores in the final models.

\section{Discussion}

In the absence of a genetic syndrome, most 1-year-old children with TOF scored within 2 SDs of normal on both 
TABLE 3. Multivariate regression models for Mental Developmental Index and Psychomotor Developmental Index

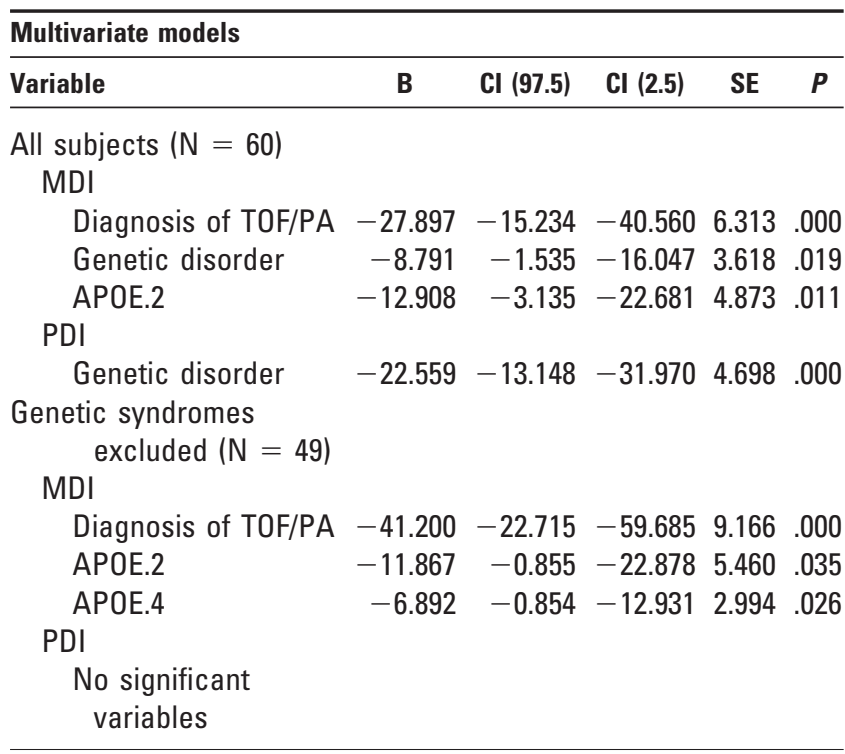

Cl, Confidence interval; $S E$, standard error; $M D I$, Mental Developmental Index; TOF/PA, tetralogy of Fallot/pulmonary atresia; $A P O E$, apolipoprotein E; PDI, Psychomotor Developmental Index.

the MDI and the PDI of the Bayley Scales of Infant Development-II. In contrast, scores on the MDI and PDI were often abnormal in patients with coexisting genetic syndromes. In one of the largest studies from Boston Children's Hospital of ND outcome in patients who have required CPB for repair of congenital heart disease, the investigators found that patients who underwent repair of TOF had poorer ND outcomes in comparison with those who underwent an arterial switch operation for transposition of the great arteries. ${ }^{9}$ Although their study did not specifically target this issue, the investigators hypothesized that the difference between the 2 groups was related to a known prevalence of genetic syndromes associated with TOF. Our data confirm this hypothesis that patients with TOF and a coexisting genetic syndrome have a greater likelihood of adverse ND outcome after complete intracardiac repair.

Despite the intended exclusion of patients with recognizable genetic or phenotypic syndromes other than chromosome $22 \mathrm{q} 11$ microdeletions, $18.3 \%$ of our study patients were subsequently found to have a genetic syndrome, underscoring the prevalence of genetic abnormalities in patients with TOF. The most common genetic disorder was 22q11 microdeletion, consistent with reports citing up to a $16 \%$ incidence of $22 \mathrm{q} 11$ microdeletion in patients with TOF. ${ }^{12}$ In a psychoeducational profile performed by Moss and associates ${ }^{21}$ patients with 22q11 microdeletions had significant weakness in visualspatial perception, problem-solving, nonverbal reason- ing, and impaired novel reasoning and concept formation, despite receiving special education for those areas. These results reflect more recent findings by Gerdes and coworkers ${ }^{22}$ and Maharasingam and coworkers ${ }^{23}$ who independently demonstrated profound delays in speech and language development in patients with 22q11 microdeletions that were independent of underlying cardiac disease or need for cardiac surgery.

In addition, genetic polymorphisms may influence a person's ability to recover from a neurologic insult. Specifically, APOE is the primary lipid transporter in the central nervous system. Its primary function is maintenance of cell membrane integrity in the neuronal cytoskeleton. APOE synthesis is up-regulated in response to neuronal injury and plays a crucial role in neuronal repair. ${ }^{18}$ There are $3 \mathrm{com}$ mon isoforms of APOE, which are encoded by 3 alleles: $\varepsilon 2$, $\varepsilon 3$, and $\varepsilon 4$. In adults, the $\varepsilon 4$ allele has been implicated as a risk factor for outcomes after central nervous system ischemia, traumatic brain injury, and cardiac surgery. ${ }^{24,25}$ More recently, Gaynor and associates ${ }^{20}$ found the APOE $\varepsilon 2$ allele predicts worse ND outcome at 1 year of age after infant repair of congenital heart defects. The current study addresses the subset of patients with TOF from that larger study. In the current study, $A P O E \varepsilon 2$ and $\varepsilon 4$ allele carriers had significantly lower MDI scores, implicating APOE genotype as a predictor in ND dysfunction after infant cardiac surgery for TOF.

Over the years, attention has been focused on the use of CPB during infancy as a cause of poor ND outcome. In this study, abnormal MDI and PDI scores were not related to intraoperative variables. Specifically, the age at the time of surgery, the use or duration of DHCA, and the total support time were not associated with worse scores. Although the neurologic sequelae of CPB have been extensively studied in adults, their impact on childhood neurodevelopment remains controversial. Prolonged duration of DHCA has been implicated by many as a significant risk factor for worse ND outcome, observing that risk increases when the duration of DHCA exceeds 45 to 50 minutes. ${ }^{7,9,10,26,27}$ In our study, the mean duration of DHCA was 30.7 minutes and neither the use nor the duration of DHCA was a risk factor for adverse ND outcome. This is similar to the findings published by Kaltman and associates, ${ }^{28}$ in which the duration of DHCA was not a risk factor for poor neurologic outcome after infant surgical closure of ventricular septal defects. The current study and others support the hypothesis that patient-specific factors are important determinants of ND outcomes after neonatal and infant cardiac surgery and contribute more substantially to the risk of adverse ND outcomes than do intraoperative management strategies. $^{29}$ 


\section{Limitations}

This study represents a post hoc analysis of a subset of patients from a larger cohort of subjects enrolled in a study designed to evaluate the association between $A P O E$ genotype polymorphisms and postoperative ND outcome. Thus, this study was not specifically powered to address the risk factors for adverse ND outcome in patients with TOF. Second, those patients who were enrolled in the study but did not return for ND assessment at 1 year did require longer $\mathrm{CPB}$ and, therefore, total support times. Third, although the finding of TOF/pulmonary atresia was a risk factor for adverse ND outcome, the small number of patients with this entity $(n=3)$ precluded any meaningful further speculation or analysis. Finally, this study is limited to the ND outcome at the 1-year benchmark. It is possible that further developmental concerns and abnormalities will be uncovered when this cohort of patient is followed over time.

\section{Conclusions}

At 1 year of age, most patients who underwent repair of TOF had normal ND scores. Intraoperative management strategies were not predictive of ND outcomes. The presence of a genetic syndrome was associated with ND delay, which likely is part of the clinical phenotype. In addition, the $A P O E$ genotype predicted adverse neurologic sequelae, suggesting that ND outcome is also influenced by factors that modulate neurologic resiliency after surgical repair of TOF. Genetic factors may explain interindividual variation in outcome and must be considered when evaluating ND outcome in patients with TOF.

\section{References}

1. Perry LW, Neill CA, Ferencz C, et al. Infants with congenital heart disease: the cases. In: Ferencz C, Rubin JD, Loffredo CA, et al, eds. Perspectives in Pediatric Cardiology. Epidemiology of Congenital Heart Disease, the Baltimore-Washington Infant Study 1981-1989. Armonk, NY: Futura; 1993:33-62.

2. Murphy JG, Gersh BJ, Mair DD, et al. Long-term outcome in patients undergoing surgical repair of tetralogy of Fallot. $N$ Engl $J$ Med. 1993;329:593-9.

3. Mahle WT, Wernovsky G. Long-term developmental outcome of children with complex congenital heart disease. Clin Perinatol. 2001; 28:235-47.

4. Limperopoulos C, Majnemer A, Shevell MI, Rosenblatt B, Rohlicek C, Tchervenkov C. Neurologic status of newborns with congenital heart defects before open heart surgery. Pediatrics. 1999;103:402-8.

5. Galli KK, Zimmerman RA, Jarvik GP, et al. Periventricular leukomalacia is common after neonatal cardiac surgery. $J$ Thorac Cardiovasc Surg. 2004;127:692-702.

6. Newburger JW, Jonas RA, Wernovsky G, et al. A comparison of the perioperative neurologic effects of hypothermic circulatory arrest versus low-flow cardiopulmonary bypass in infant heart surgery. $N$ Engl J Med. 1993:329:1057-64.

7. Bellinger DC, Jonas RA, Rappaprt LA, et al. Developmental and neurologic status of children at 4 years of age after heart surgery with hypothermic circulatory arrest or low-flow cardiopulmonary bypass. Circulation. 1999;100:526-32.
8. Bellinger DC, Wypij D, du Plessis AJ, et al. Eight-year neurodevelopmental status: The Boston Circulatory Arrest Study. Circulation. 2000;102:II-497.

9. Bellinger DC, Wypij D, du Plessis AJ, et al. Developmental and neurologic effects of alpha-stat versus Ph-stat management strategies for deep hypothermic cardiopulmonary bypass in infants. $J$ Thorac Cardiovasc Surg. 2001;121:374-83.

10. Forbess JM, Visconti KJ, Hancock-Friesen C, Howe RC, Bellinger DC, Jonas RA. Neurodevelopmental outcome after congenital heart surgery: results from an institutional registry. Circulation. 2002; 106[suppl II-]:95-102.

11. Michielon G, Marino B, Formigari R, et al. Genetic syndromes and outcome after surgical correction of tetralogy of Fallot. Ann Thorac Surg. 2006;81:968-75.

12. Goldmuntz E, Clark BJ, Mitchell LE, et al. Frequency of 22q11 deletions in patients with conotruncal defects. J Am Coll Cardiol. 1998:32:492-8.

13. Marino B, Digilio MC, Grazioli S, et al. Associated cardiac anomalies in isolated and syndromic patients with tetralogy of Fallot. Am J Cardiol. 1996;77:505-8.

14. McElhinney DB, Krantz ID, Sason L, et al. Analysis of cardiovascular phenotype and genotype correlation in individuals with JAG1 mutation and/ or Alagille syndrome. Circulation. 2002;106:2567-74.

15. Goldmuntz E. The epidemiology and genetics of congenital heart disease. Clin Perinatol. 2001;28:1-10.

16. Hovels-Gurich HH, Konrad K, Skorzenski D, et al. Long-term neurodevelopmental outcome and exercise capacity after corrective surgery for tetralogy of Fallot or ventricular septal defect in infancy. Ann Thorac Surg. 2006;81:958-67.

17. DeMaso DR, Beardslee WR, Silbert AR, Flyer DC. Psychological functioning in children with cyanotic heart defects. J Dev Behav Pediatr. 1990;11:289-94.

18. Laskowitz DT, Horsburgh K, Roses AD. Apolipoprotein E and the CNS response to injury. J Cereb Blood Flow Metab. 1998;18:465-71.

19. Schiefermeier M, Kollegger H, Madi C, et al. Apolipoprotein E polymorphism survival and neurological outcome after cardiopulmonary resuscitation. Stroke. 2000;31:2068-73.

20. Gaynor JW, Gerdes M, Zackai EH, et al. Apolipoprotein E genotype and neurodevelopmental sequelae of infant cardiac surgery. J Thorac Cardiovasc Surg. 2003;126:1736-45.

21. Moss EM, Batshaw ML, Solot CB, et al. Psychoeducational profile of the 22q11 microdeletion: a complex pattern. J Pediatr. 1999;134:193-8.

22. Gerdes M, Solot S, Wang PP, McDonald DM, Zackai EH. Taking advantage of early diagnosis: preschool children with the 22q11 deletion. Genet Med. 2001;3:40-4.

23. Maharasingam M, Ostman-Smith I, Pike MG. A cohort study of neurodevelopmental outcome in children with DiGeorge syndrome following cardiac surgery. Arch Dis Child. 2003;88:61-4.

24. Tardiff E, Newman MF, Saunders AM, et al. Preliminary report of a genetic basis for cognitive decline after cardiac operations. Ann Thorac Surg. 1997;64:715-20.

25. Steed L, Kong R, Stygall J, et al. The role of apolipoprotein E in cognitive decline after cardiac operation. Ann Thorac Surg. 2001;71:823-6.

26. Oates R, Simpson J, Turnbull J, et al. The relationship between intelligence and duration of circulatory arrest with deep hypothermia. J Thorac Cardiovasc Surg. 1995;110:786-92.

27. Wypij D, Newberger JW, Rappaport LA, et al. The effect of deep hypothermic circulatory arrest in infant heart surgery on late neurodevelopment: The Boston Circulatory Arrest Trial. Thorac Cardiovasc Surg. 2003;126:1397-403.

28. Kaltman JR, Jarvik GP, Bernbaum J, et al. Neurodevelopmental outcome following early repair of ventricular septal defect with or without aortic arch obstruction. J Thorac Cardiovasc Surg. 2006;131:792-8.

29. Gaynor JW, Wernovsky G, Jarvik, GP, et al. Patient characteristics are important determinants of neurodevelopmental outcome at one-year of age following neonatal and infant cardiac surgery. $J$ Thorac Cardiovasc Surg. 2007;133:1344-53. 